\title{
Efficiency in Ofloxacin Antibiotic Water Remediation by Magnetic Zeolites Formed Combining Pure Sources and Wastes
}

\author{
Claudia Belviso ${ }^{1, *(\mathbb{D}}$, Giulia Guerra ${ }^{2}$, Maryam Abdolrahimi ${ }^{3,4}{ }^{(0}$, Davide Peddis $^{4,5}$, Federica Maraschi ${ }^{2}(\mathbb{D}$, \\ Francesco Cavalcante $^{1}$, Maurizio Ferretti ${ }^{5}$, Annalisa Martucci ${ }^{6}$ (D) and Michela Sturini ${ }^{2}(\mathbb{D})$ \\ 1 Istituto di Metodologie per l'Analisi Ambientale, IMAA-CNR, 85050 Potenza, Italy; \\ francesco.cavalcante@imaa.cnr.it \\ 2 Department of Chemistry, University of Pavia, 27100 Pavia, Italy; giulia.guerra01@universitadipavia.it (G.G.); \\ federica.maraschi@unipv.it (F.M.); michela.sturini@unipv.it (M.S.) \\ 3 Dipartimento di Scienze, Università degli Studi Roma Tre, 00146 Roma, Italy; \\ maryam.abdolrahimi@uniroma3.it \\ 4 Istituto di Struttura della Materia, ISM-CNR, 00015 Rome, Italy; davide.peddis@unige.it \\ 5 Dipartimento di Chimica e Chimica Industriale, Università di Genova, 16146 Genova, Italy; \\ ferretti@chimica.unige.it \\ 6 Department of Physics and Earth Sciences, University of Ferrara, 44122 Ferrara, Italy; mrs@unife.it \\ * Correspondence: claudia.belviso@imaa.cnr.it
}

\section{check for}

updates

Citation: Belviso, C.; Guerra, G.; Abdolrahimi, M.; Peddis, D.;

Maraschi, F.; Cavalcante, F.; Ferretti,

M.; Martucci, A.; Sturini, M.

Efficiency in Ofloxacin Antibiotic Water Remediation by Magnetic Zeolites Formed Combining Pure Sources and Wastes. Processes 2021, 9 2137. https://doi.org/10.3390/ pr9122137

Academic Editor: Farooq Sher

Received: 31 August 2021

Accepted: 22 November 2021

Published: 26 November 2021

Publisher's Note: MDPI stays neutra with regard to jurisdictional claims in published maps and institutional affiliations.

Copyright: (c) 2021 by the authors. Licensee MDPI, Basel, Switzerland. This article is an open access article distributed under the terms and conditions of the Creative Commons Attribution (CC BY) license (https:// creativecommons.org/licenses/by/ $4.0 /)$

\begin{abstract}
In this work, red mud (RM) and spinel iron oxide nanoparticles (SPIONs) were added to pure silica/alumina sources (SAs) and fly ash (FA) with the aim of synthesizing and investigating the magnetic behavior of different zeolites. SAs were used to synthesize zeolite with LTA topology (zeolite A) with the addition of both red mud and spinel iron oxide nanoparticles. FA and RM were mixed to synthesize sodalite whereas only FA with the addition of SPIONs was used to form zeolite with FAU-topology (zeolite X). All the synthetic products showed magnetic properties. However, zeolites with spinel iron oxide nanoparticles (zeolites A and X) showed ferromagnetic-like behavior. Sodalite was characterized by a reduction in saturation magnetization, whereas zeolite A with red mud displayed antiferromagnetic behavior. For the first time, all the synthetic products were tested for polluted water remediation by a persistent emerging contaminant, ofloxacin (OFL) antibiotic. The four zeolite types showed good adsorption affinity towards OFL under actual conditions (tap water, natural $\mathrm{pH}$ ). All materials were also tested for OFL removal in real waters spiked with OFL $10 \mu \mathrm{g} \mathrm{L}^{-1}$. Satisfactory recoveries (90-92\% in tap water, $83-87 \%$ in river water) were obtained for the two zeolites synthesized from industrial waste materials.
\end{abstract}

Keywords: zeolites; wastes; nano-magnetite; magnetic properties; ofloxacin antibiotic; water depollution

\section{Introduction}

According to the Subcommittee on Zeolites of the International Mineralogical Association, Commission on New Minerals and Mineral Names [1] "zeolites are microporous crystalline materials with a structure characterized by a framework of linked $\mathrm{TO}_{4}$ tetrahedra (where $\mathrm{T}=\mathrm{Si}, \mathrm{Al}, \mathrm{Be}, \mathrm{P}, \mathrm{Zn}$ or others), each consisting of four $\mathrm{O}$ atoms surrounding a cation. The structure contains channels, channel intersections and/or cages usually occupied by $\mathrm{H}_{2} \mathrm{O}$ molecules and extra-framework cations that are commonly exchangeable." This zeolite definition refers not only to the natural phases but also to synthetic materials. These last can crystallize with specific structures and different properties depending on the utilization of pre-designed organic additives (SDAs), the nature and concentration of alkali metal ions, heteroatom substitution, the time and temperature of crystallization, $\mathrm{pH}, \mathrm{Si} / \mathrm{Al}$ and $\mathrm{H}_{2} \mathrm{O} / \mathrm{SiO}_{2}$ ratios, topotactic transformations, charge density mismatch, stirring, etc. [2-6]. However, synthetic zeolites are characterized by other properties such as well-defined micropore dimension, high porosity, and surface area, making them good candidates for soil [7-14] and polluted water remediation [15-20]. 
The literature reports the synthesis of zeolites using many raw materials [21-24], including wastes [25-28]. The approaches based on the use of sustainable routes for synthesis of zeolites to deal with environmental problems are very intriguing. In recent years fly ash (FA) and red mud (RM) have been used to form magnetic zeolites such as FAU, 4A, ZSM-5, GIS, and X zeolites [29-33].

The combustion of coal in thermal power plants determines the production of fly ash. Due to its chemical composition, potentially characterized by the presence of toxic elements, this material is classified as a waste material to be disposed of in landfill. On the other hand, the main FA component is amorphous aluminosilicate glass, thus making this waste useful for zeolite synthesis. Red mud is a waste product produced by the caustic leaching process to extract aluminum from bauxite. It is chemically characterized by the presence of alumina and a high amount of iron oxy-hydroxides; thus, RM is expected to induce magnetic behavior when used to synthesize zeolites [31-33]. Among the other phases, some samples of red mud also show the presence of natrojarosite and $\mathrm{Pb}$-natrojarosite, thus increasing their toxicity, generally connected with the high $\mathrm{pH}$ [34].

In the last few years, the application of magnetic zeolites in polluted water treatments has been well documented [35-37]. These materials can be useful to adsorb heavy metals (HM), persistent and mobile organic compounds (PMOCs), organic dyes and polymer-coated magnetic particles [35], and radio nuclides [38], as well as to accelerate the coagulation of sewage [39]. These materials are even more attractive due to their ability to be easily separated from the medium using an external magnetic field.

PMOCs, as well as a wide range of other hazardous pollutants, are emerging contaminants (ECs) which are released from many sources, thus determining diffuse pollution, mainly regarding environmental waters [40-45]. ECs enter the aquatic environment mainly through wastewater due to their low biodegradability in urban wastewater treatment plants (WWTPs). Despite the low concentrations, from ng to a few $\mu \mathrm{g} \mathrm{L}^{-1}$, they have a significant probability of being toxic [46,47]. Among these, antibiotics are of particular concern since their large use in human as well as in veterinary medicine contributes to the generation of antibiotic-resistant bacteria and antibiotic-resistant genes [48,49]. For the reasons mentioned above, it is mandatory to find new strategies to remove them [48,50,51].

In this study, different zeolites were synthesized using pure reagents or fly ash as the silica/alumina sources, and spinel iron oxides (i.e., magnetite or maghemite) and Fe oxides/hydroxides from red mud to confer magnetic properties. To the best of our knowledge, such materials were tested here for the first time for removing ofloxacin (OFL) under relevant environmental conditions (i.e., tap and river water, natural $\mathrm{pH}$, microgram per liter concentration). Due to our previous investigations on the antibiotic fluoroquinolone's (FQ) behavior towards natural and synthetic substrates [52-55], OFL was chosen as a model molecule in these new experiments. Kinetic and equilibrium studies were performed in tap water to evaluate the adsorption properties of such materials towards OFL, while structural investigations were performed on the materials, before and after antibiotic loading, to elucidate the adsorption mechanism. The removal efficiency was also evaluated under representative conditions, viz. a few micrograms per liter river water. Such results can provide useful information for future research on adsorption technology $[47,56]$.

\section{Materials and Methods}

\subsection{Materials}

Sodium silicate, fly ash (Cerano, Brindisi, Italy), and sodium aluminate were used as silica and alumina sources. Spinel iron oxide nanoparticles (SPIONs), and two samples of red mud from Sulcis, Cagliari (Italy) (RMs) and from Podgorica (Montenegro) (RMp) were also used, along with sodium hydroxide pellets. All chemicals of reagent grade were purchased from Aldrich Chemicals Ltd. (Burlington, MA, USA).

High Performance Liquid Chromatography (HPLC) gradient-grade acetonitrile (ACN) was purchased by VWR International (Milano, Italy), $\mathrm{H}_{3} \mathrm{PO}_{4}(85 \%$ w/w) and water for 
LC/MS by Carlo Erba Reagents (Cornaredo, Milano, Italy), OFL VETRANAL ${ }^{\circledR}$, analytical standard by Merck Life Science S.r.l. (Milano, Italy).

Aqueous OFL stock solution $\left(293 \mathrm{mg} \mathrm{L}^{-1}\right)$ was prepared in tap water and stored in the dark at $4{ }^{\circ} \mathrm{C}$ before use.

Structures and chemical characteristics of OFL antibiotic under investigation are reported in Figure 1.

\section{Ofloxacin (OFL): $\mathrm{C}_{18} \mathrm{H}_{20} \mathrm{FN}_{3} \mathrm{O}_{4}$}

\section{Molar Mass: $361.373 \mathrm{~g} \cdot \mathrm{mol}-1$ Solubility: $28.3 \mathrm{mg} / \mathrm{mL}$ pKa1: 5.97 (carboxylic acid); \\ pKa2: 9.28 (piperizinyl ring) Dimensions: $12.06 \times 7.11 \AA$}

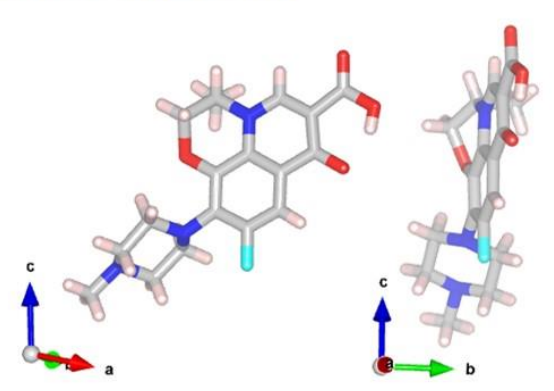

Framework type FAU

Channel dimensionality: 3-dimensional

Material Name: Faujasite

ChemicalFormula: |(Ca,Mg, $\left.\mathrm{Na}_{2}\right)_{29}\left(\mathrm{H}_{2} \mathrm{O}\right)_{240} \mid\left[\mathrm{Al}_{58} \mathrm{Si}_{134} \mathrm{O}_{384}\right]-\mathrm{FAU}$

Framework Density: $12.7 \mathrm{~T} / 1000 \AA^{3}$

Channels: $<111>127.4 \times 7.4^{\star \star \star}$

\section{Framework type LTA}

Channel dimensionality: 3-dimensional

Material Name: Linde Type A (zeolite A)

Chemical Formula: $\left|\mathrm{Na}_{12}\left(\mathrm{H}_{2} \mathrm{O}\right)_{278}\right|_{8}\left[\mathrm{Al}_{12} \mathrm{Si}_{12} \mathrm{O}_{48}\right]_{8}$-LTA

Framework Density: $14.2 \mathrm{~T} / 1000 \AA^{3}$

Channels: $<100>84.1 \times 4.1^{\star \star \star}$
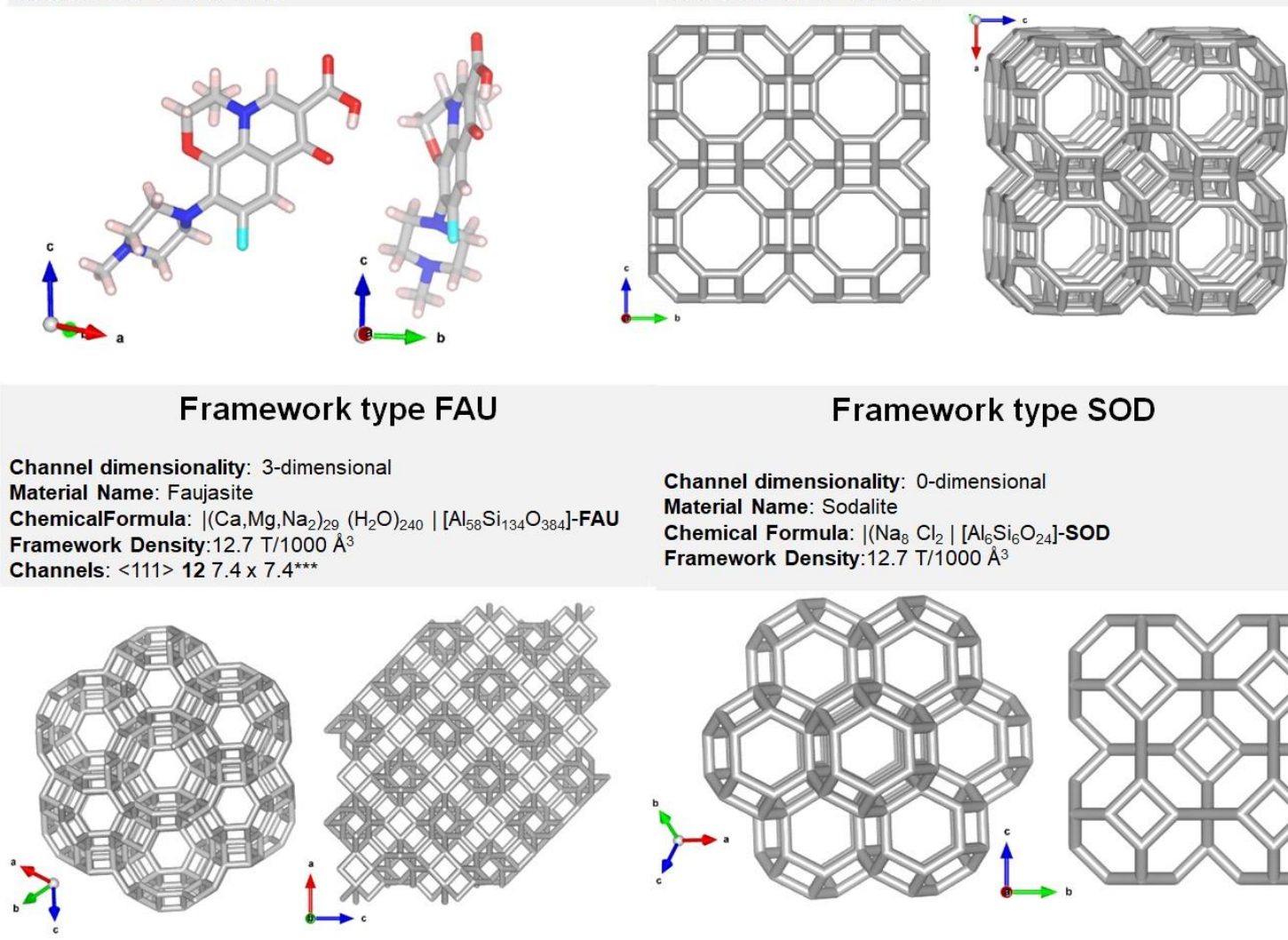

\section{Framework type SOD}

Channel dimensionality: 0-dimensional

Material Name: Sodalite

Chemical Formula: $\mid\left(\mathrm{Na}_{8} \mathrm{Cl}_{2} \mid\left[\mathrm{Al}_{6} \mathrm{Si}_{6} \mathrm{O}_{24}\right]-\mathrm{SOD}\right.$

Framework Density:12.7 T/1000 $\AA^{3}$

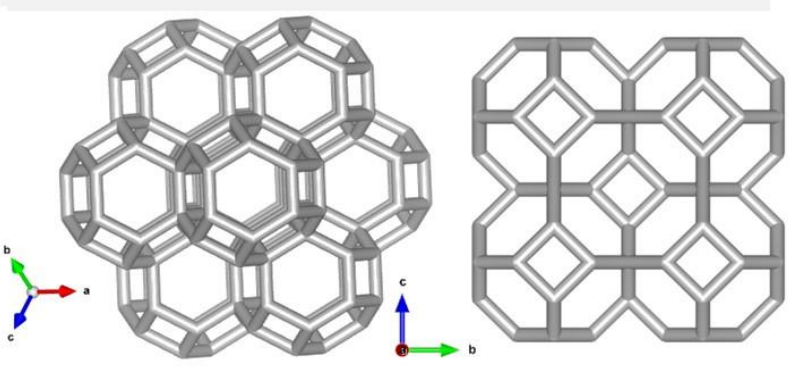

Figure 1. Structural and chemical characteristics of OFL antibiotic and zeolites formed. References for 3D structures [57-60], $* * *=\AA$.

\subsection{Zeolite Synthesis}

The synthesis using pure silica and alumina sources was carried out as described in our previous paper [34] adding SPIONs and red mud during the process (in separate experiments). The hydrothermal process was performed at $40{ }^{\circ} \mathrm{C}$. The samples were labelled SAnM and SARMs, respectively (Table S1).

The synthesis with FA and SPIONs or red mud (RMp) was performed using the modified method described in Belviso et al., [31,61], respectively. In both cases, the hydrothermal process was carried out at $60^{\circ} \mathrm{C}$. The samples were labeled FAnM and FARMp, respectively (Table S1).

\subsection{Characterization of Wastes and Zeolites}

Chemical analyses of wastes were performed by X-ray fluorescence (XRF) (Philips PW 1480), whereas the mineralogical composition of the raw materials and synthetic products was analyzed by X-ray powder diffraction (XRD). A Rigaku Rint 2200 powder diffractometer with $\mathrm{Cu}-\mathrm{Ka}$ radiation was used. The XRD patterns were collected in the 
angular range $3-70^{\circ} 2 \theta$, step-size of 0.02 , scan-step time of $3 \mathrm{~s}$, accelerating voltage of $40 \mathrm{kV}$, and electric current of $30 \mathrm{~mA}$. The ratio of crystalline (\%) to non- or nano-crystalline species in all investigated samples was determined by careful evaluation of the baseline to peak separation using the software DIFFRAC.EVA [62].

Scanning electron microscopy (SEM, Zeiss Supra 40) equipped with an energy dispersive spectrometer (EDS) was used to perform morphological observations on all the samples.

A vibrating sample magnetometer (VSM Model 10-Microsense) equipped with an electromagnet producing a magnetic field in a range from -2 to $+2 \mathrm{~T}$ was used to investigate the field dependence of magnetization.

\subsection{Analytical Measurements}

A UVmini-1240 UV-Vis spectrophotometer (Shimadzu Corporation, Milano, Italy) was used to perform the adsorption experiments. The wavelength selected for analysis was $280 \mathrm{~nm}$ corresponding to the maximum OFL adsorption.

Calibration with six standards at concentrations between 1 and $10 \mathrm{mg} \mathrm{L}^{-1}$ yielded optimal linearity $\left(\mathrm{R}^{2}>0.9999\right)$. The quantification limit was $0.8 \mathrm{mg} \mathrm{L}^{-1}$.

HPLC system characterized by a Series 200 pump (Perkin Elmer, Milano, Italy) equipped with a programmable fluorescence detector (FD) and a vacuum degasser was used to perform the kinetic experiments and OFL adsorption at $10 \mu \mathrm{g} \mathrm{L}^{-1}$. The fluorescence excitation/emission wavelengths selected were $280 / 450 \mathrm{~nm}$. A $50 \mu \mathrm{L}$ quantity of each sample was filtered $(0.22 \mu \mathrm{m}$ nylon syringe filter $)$ and injected into a $250 \times 4.6 \mathrm{~mm}$, $5 \mu \mathrm{m}$ Ascentis RPAmide (Supelco-Merck Life Science, Milano, Italy) coupled with a similar guard-column. The mobile phase was $25 \mathrm{mM} \mathrm{H}_{3} \mathrm{PO}_{4}-\mathrm{ACN}$ (85:15); the flow rate $1 \mathrm{~mL} \mathrm{~min}^{-1}$.

Optimal linearity $\left(\mathrm{R}^{2}>0.9997\right)$ was yielded when performing the calibration with six standards in the range $1-10 \mu \mathrm{g} \mathrm{L}^{-1}$. The quantification limit was $0.9 \mu \mathrm{g} \mathrm{L}^{-1}$.

\subsection{Adsorption and Kinetic Experiments}

OFL adsorption on SAnM, SARMs, FAnM, and FARMp was studied using a batch mode. A $100 \mathrm{mg}$ quantity of each material was mixed with $10 \mathrm{~mL}$ of OFL tap water solutions at concentrations in the range $10-293 \mathrm{mg} \mathrm{L}^{-1}$. The solution $\mathrm{pH}$ was adjusted to around 7 with the addition of $50 \mu \mathrm{L} 1 \mathrm{M} \mathrm{HCl}$. Subsequently, the tubes were wrapped with aluminum foil to prevent light-induced drug decomposition and shaken (orbital shaker) at room temperature for $24 \mathrm{~h}$. After equilibration, the adsorbent was separated and filtered $(0.22 \mu \mathrm{m}$ nylon syringe filter), and the OFL concentration (Ce) in the liquid phase was determined.

The adsorbed OFL amount at equilibrium $\left(q_{e}, \mathrm{mg} \mathrm{g}^{-1}\right)$ was calculated by Equation (1):

$$
q_{e}=\frac{\left(C_{0}-C_{e}\right) \times V}{M}
$$

where $C_{0}$ is the initial concentration of OFL $\left(\mathrm{mg} \mathrm{L}^{-1}\right), C_{e}$ the concentration of OFL in solution at equilibrium $\left(\mathrm{mg} \mathrm{L}^{-1}\right), V$ the volume of the solution (L), and $M$ the amount of the adsorbent $(\mathrm{g})$.

For the kinetic experiments, $200 \mathrm{mg}$ of each material was suspended in $20 \mathrm{~mL}$ of tap water with an initial OFL concentration of $10 \mathrm{mg} \mathrm{L}^{-1}$ to guarantee an adsorption efficiency in the range of 10-85\% (ASTM D3860 [63]). The suspensions were stirred (glass stirring rod) throughout the experiment. At planned times, the stirring was stopped, and $50 \mu \mathrm{L}$ supernatant was collected in the range 0-60 min. Subsequently, it was diluted to 5 or $10 \mathrm{~mL}$ tap water, filtered using a $0.22 \mu \mathrm{m}$ nylon syringe filter, and finally injected in the HPLC-FD system to determine the concentration of OFL at time $t\left(C_{t}\right)$. 
The adsorbed OFL amount at time $\mathrm{t}\left(q_{t}, \mathrm{mg} \mathrm{g}^{-1}\right)$ was calculated following Equation (2):

$$
q_{t}=\frac{\left(C_{0}-C_{t}\right) \times V}{M}
$$

where $C_{0}$ is the initial concentration of OFL $\left(\mathrm{mg} \mathrm{L}^{-1}\right), C_{t}$ the concentration of OFL in solution at time $t\left(\mathrm{mg} \mathrm{L}^{-1}\right), V$ the volume of the solution (L), and $M$ the amount of the adsorbent (g).

The experiments were carried out in triplicate with good reproducibility (RSD $\leq 10 \%$ ). The control sample (tap water solutions containing OFL and no adsorbent phase) showed no change in OFL concentration.

A dedicated software (OriginPro, Version 2019b. OriginLab Corporation, Northampton, MA, USA) was used to calculate the thermodynamic and kinetic parameters.

\section{Results}

\subsection{Magnetic Properties of Synthetic Zeolites}

Table S2 displays the chemical composition of the red mud and fly ash. The data confirmed the high percentage of $\mathrm{Fe}_{2} \mathrm{O}_{3}$ in both $\mathrm{RM}$ samples (36.80 and 37.04\%, respectively) and the large amount of $\mathrm{SiO}_{2}(46.80 \%)$ and $\mathrm{Al}_{2} \mathrm{O}_{3}(28.21 \%)$ in FA. Moreover, the XRD pattern of the RMs indicated the presence of natrojarosite and franklinite (Figure S1a); the RMp showed hematite/goethite/pyrite and gibbsite with a lower amount of calcite and sodalite (Figure S1b), whereas the FA was mainly characterized by amorphous aluminosilicates and, subordinately, hematite (Figure S1c).

Zeolite A (LTA topology) crystallized from pure silica/alumina sources with the addition of both SPIONs and RMs (Figures 2 and 3). However, the XRD pattern of SAnM (Figure 2a) also showed the presence of SPIONs. This result is confirmed by the SEM images in Figure $2 b$ showing the typical cubic morphology of zeolite with LTA topology and crystals of SPIONs precipitated on the zeolite surfaces [34]. The amorphous fraction in SAnM corresponds to $\sim 13 \%$ (crystallinity estimated from 2 to $70^{\circ} 2 \theta$ ). The X-ray pattern of SARMs shows the peaks of zeolite A and hematite (Figure 3a); the amorphous fraction increases up to $\sim 21.5 \%$. Zeolite morphology is displayed in Figure $3 b$.

Field dependence of magnetization (full symbols) and remanent magnetization measured by Direct Current Demagnetization (DCD) protocol (empty symbol) has been reported in Figure 4 for all the samples. In a typical DCD measurement, the sample is saturated in an external field of $-5 \mathrm{~T}$, then the external field is removed, and the remanence magnetization is recorded. To invert the magnetization, the sample is then exposed to a reverse positive field $\left(\mathrm{H}_{\mathrm{rev}}\right)$ then $\mathrm{H}_{\mathrm{rev}}$ is removed and the remanence magnetization is recorded. $\mathrm{M}_{\mathrm{DCD}} \mathrm{Vs}$. $\mathrm{H}_{\mathrm{rev}}$ represents merely the irreversible part of the magnetization, allowing the determination of a value of remanence coercivity (i.e., $\mathrm{H}_{\mathrm{Cr}}$, reverse field for which $\mathrm{M}_{\mathrm{DCD}}=0$ ) excluding the reversible phenomena (i.e., superparamagnetic relaxation). The differentiated remanence curves (i.e., $\mathrm{dM}_{\mathrm{DCD}}(\mathrm{H}) / \mathrm{dH}$ ) reported in Figure $\mathrm{S} 2$ for FAnM (full square) and FARMs (empty square) represent the irreversible component of the susceptibility ( $\chi$ irr) [64]. This quantity can be considered as a measure of the distribution of the energy barrier, which is associated with the switching field distribution (SFD) in a nanoparticle system [65].

The M vs. H curve of the SAnM sample mimics the ferromagnetic behavior of pure SPIONs (Figure S3a), with a strong expected reduction of Ms (Table 1) due to a lower content of magnetic phase. Switching field distribution (Figures $4 \mathrm{a}$ and S3b) and values of Hc/HCR (Table 1) are equal within the experimental error in SAnM and SPIONs sample, strongly suggesting that the synthesis process does not affect the magnetic properties of SPIONs. 

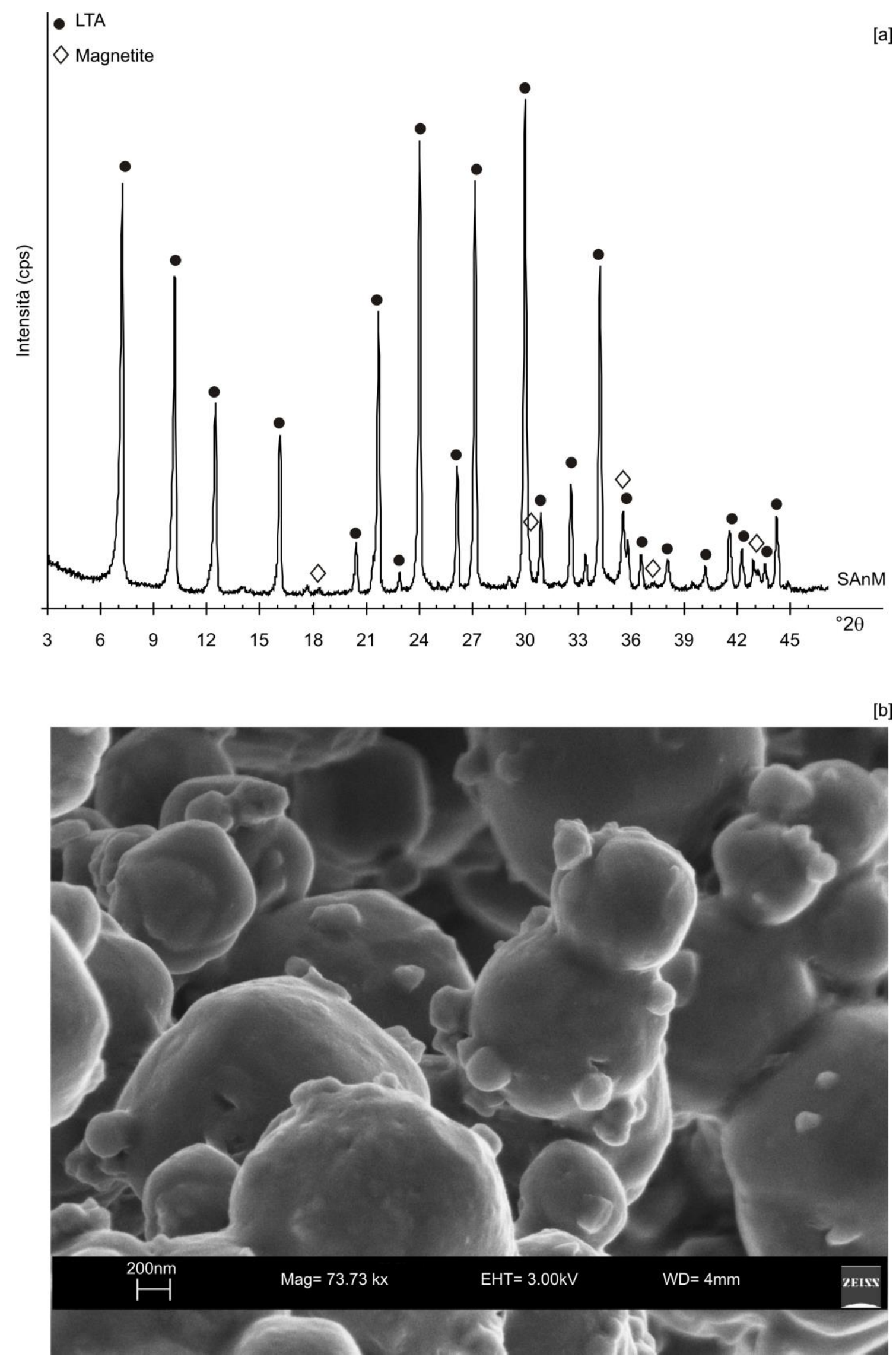

Figure 2. XRD pattern (a) and SEM image (b) of SAnM sample. 


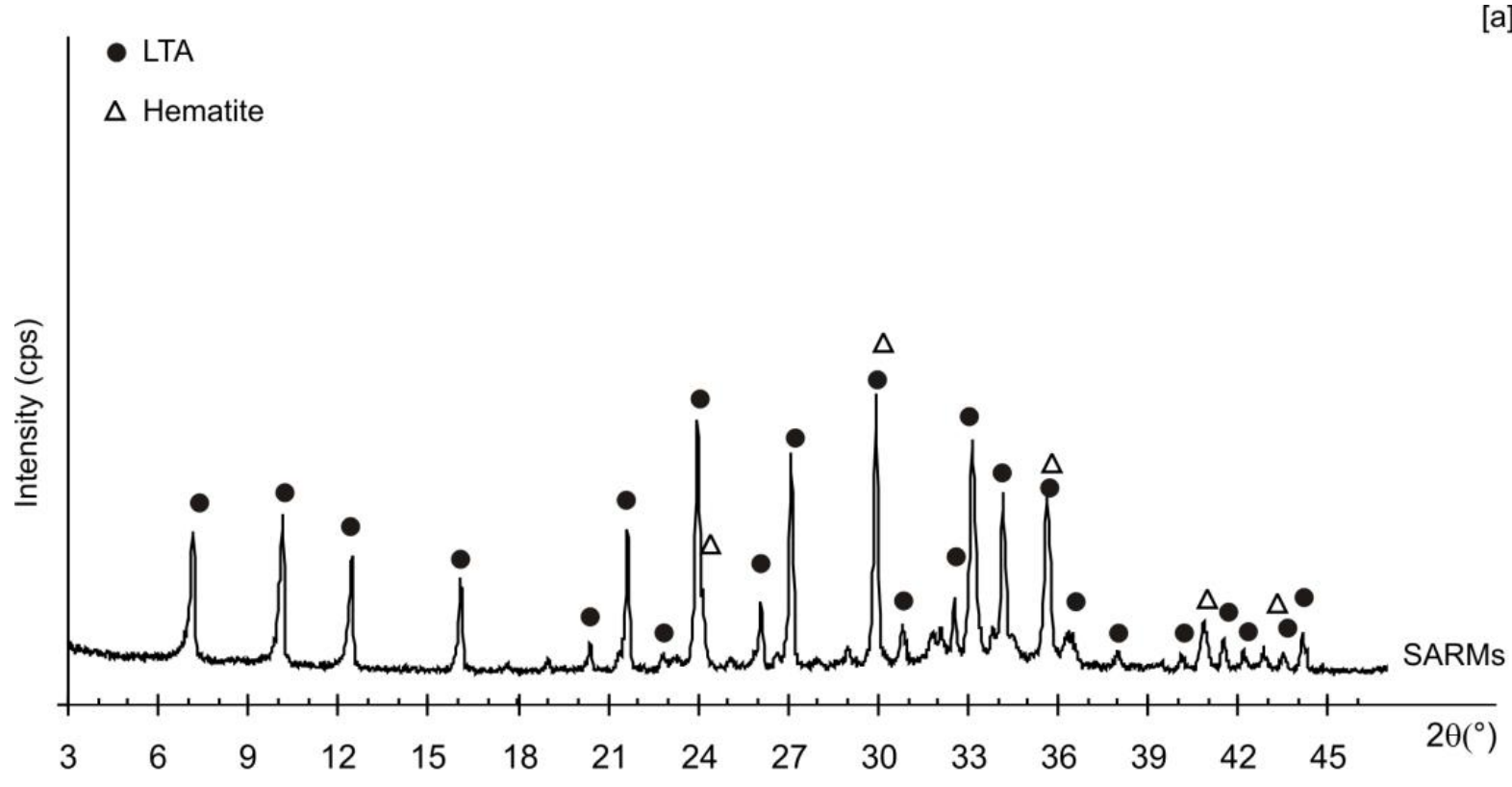

[b]

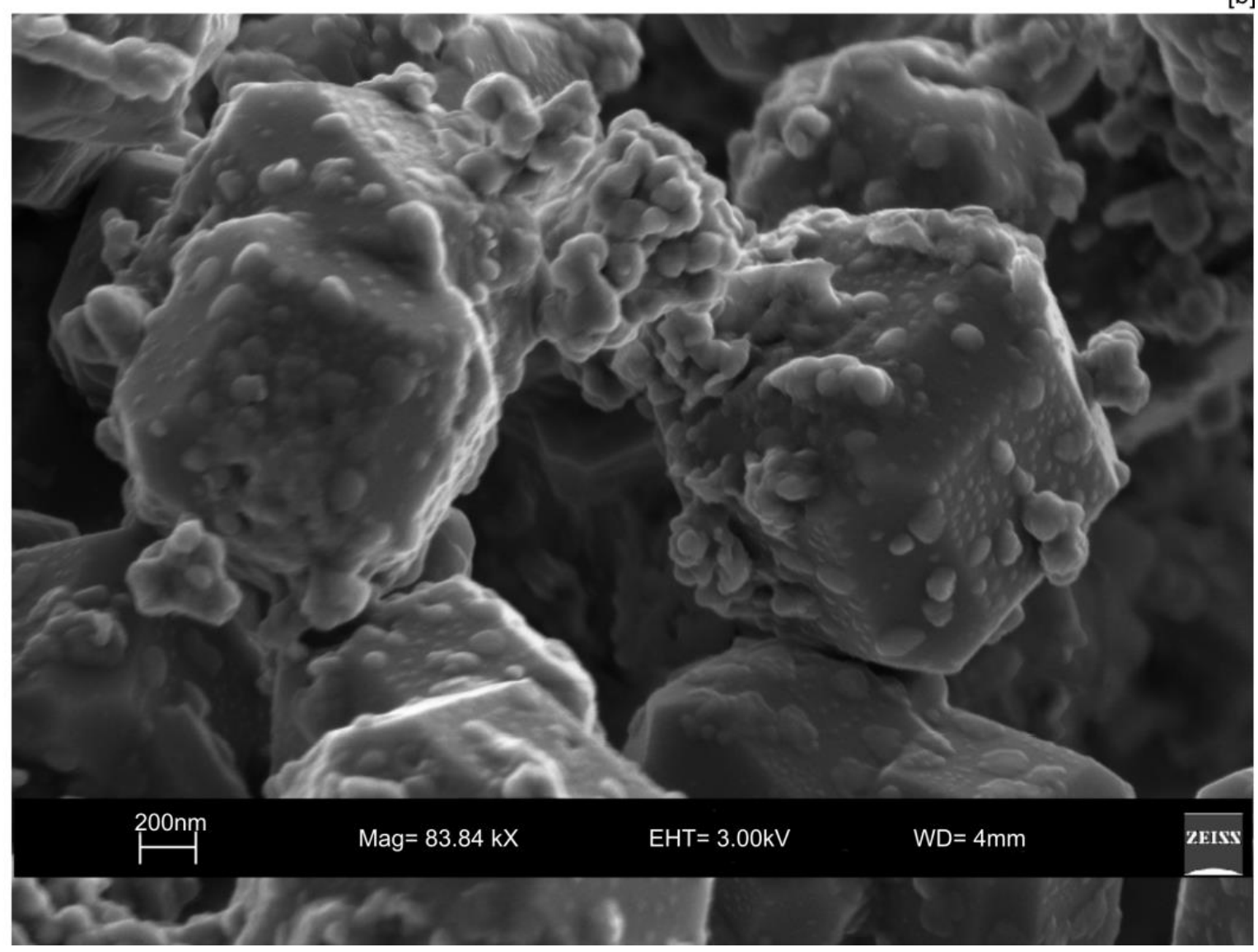

Figure 3. XRD pattern (a) and SEM image (b) of SARM sample. 

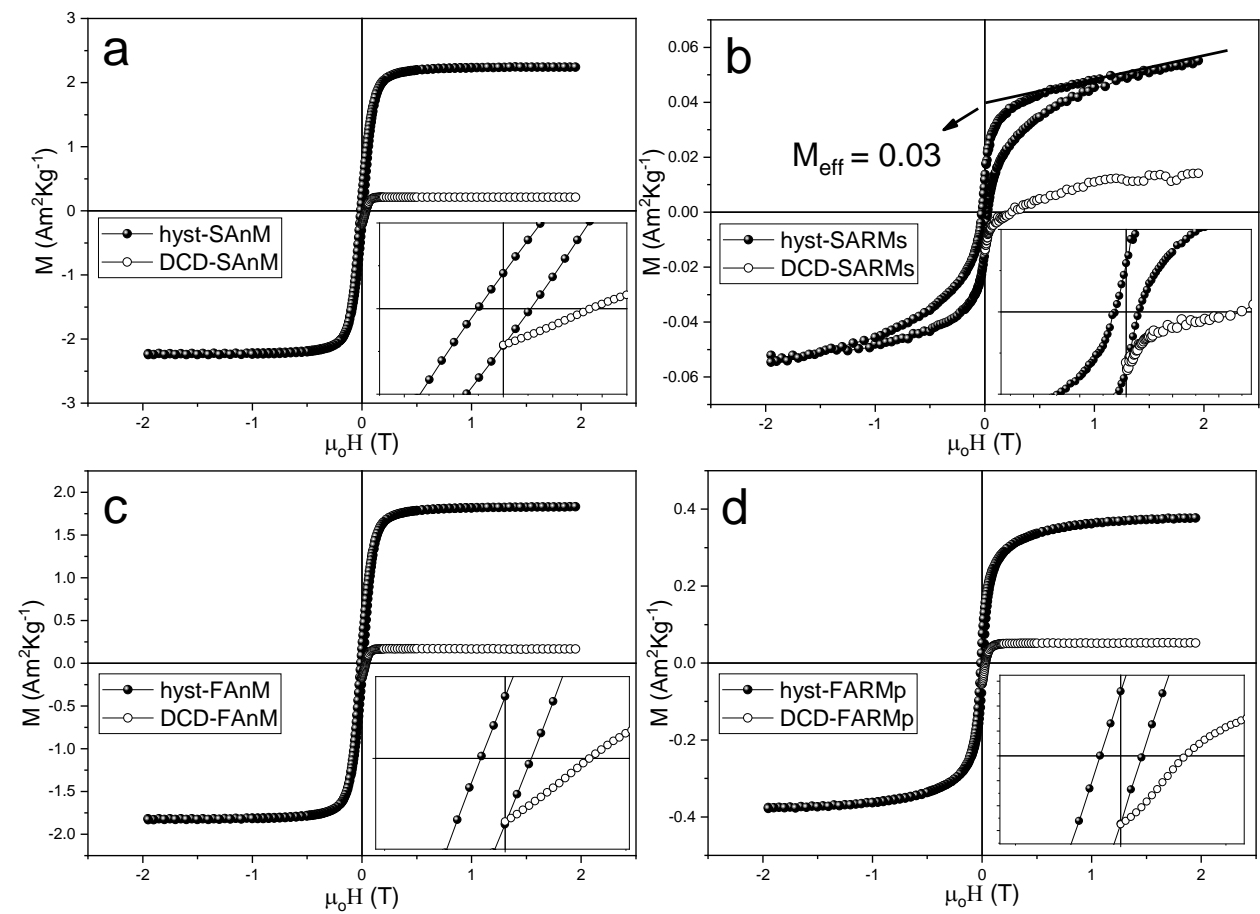

Figure 4. Room temperature hysteresis curves (full symbols) and DCD remanent magnetization curves (empty symbols) of (a) SAnM and (b) SARMs, (c) FAnM, and (d) FARMp.

Table 1. Saturation Magnetization (Ms) coercive field $\left(\mathrm{H}_{\mathrm{c}}\right)$ extracted from hysteresis recorded at $300 \mathrm{~K}$. Remanence Coercivity $\left(\mathrm{H}_{\mathrm{Cr}}\right)$ extracted from DCD recorded at $300 \mathrm{~K}$. Uncertainties in the last digit are given in parentheses.

\begin{tabular}{cccc}
\hline Sample & $\mathbf{M s}\left(\mathbf{A m}^{\mathbf{2}} \mathbf{k g}^{-\mathbf{1})}\right.$ & $\mathbf{H}_{\mathbf{c}}(\mathbf{m T})$ & $\mathbf{H}_{\mathbf{C r}}(\mathbf{m T})$ \\
\hline SAnM & $2.2(5)$ & $11.0(1)$ & $36.0(2)$ \\
SARMs & $0.07(5)$ & $27.0(1)$ & $244.0(5)$ \\
FAnM & $1.9(5)$ & $10.0(1)$ & $35.0(2)$ \\
FARMp & $0.4(5)$ & $10.0(1)$ & $31.0(2)$ \\
SPIONs & $88.2(5)$ & $11.0(1)$ & $32.0(2)$ \\
\hline
\end{tabular}

The magnetic behavior dramatically changed in the sample SARMs, showing an antiferromagnetic (i.e., not saturating tendency at high field) contribution superimposed on a ferromagnetic-like component (Figure $4 \mathrm{~b}$ ). To quantify the origin of the ferro(ferri)magnetic component, the effective magnetic moment $\left(\mathrm{M}_{\text {eff }}\right)$ was determined by the extrapolation to zero of the high-field parts of the hysteresis [31]. The value of $\mathrm{M}_{\mathrm{eff}}$ in the SARMs sample was around $0.03 \mathrm{Am}^{2} \mathrm{~kg}^{-1}$, which is on the same order of magnitude as nanostructured hematite $\left(<0.5 \mathrm{Am}^{2} \mathrm{~kg}^{-1}\right)$ [66], suggesting that the small ferromagnetic-like contribution could have been due to the uncompensated spin of nanostructured hematite in agreement with XRD results. Interestingly, a quite strong anisotropy (i.e., enlargement of the hysteresis loop in the region 0.3 to $-1 \mathrm{~T}$ ) was observed as confirmed by relatively high value of coercivity $(\mathrm{Hc} \sim 27 \mathrm{mT}$ ) and remanence coercivity $(\mathrm{Hcr} \sim 244 \mathrm{mT})$. This increase in anisotropy can be ascribed to magnetoelastic components of anisotropy, strictly related to the nanoparticle shape, already observed in hematite nanoparticles [64].

Figure 5a shows the XRD pattern of the FAnM sample. The use of FA as silica/alumina source confirms the formation of zeolite X (FAU topology) (database_code 0006772 amcsdAmerican Mineralogy Crystal Structure Database); peaks referable to precipitated SPIONs (database_code 0002400 amcsd-American Mineralogy Crystal Structure Database) were also detectable. The estimated amorphous content corresponds to $\sim 32.6 \%$. The hydrothermal treatment at $60^{\circ} \mathrm{C}$ and the following aging of the FA and RM mixture determined the formation of more stable sodalite (Figure $5 b$ ). Relict zeolite $X$ and aluminosilicate were also 
detectable. RMp was used to form this type of zeolite due to its higher amount of $\mathrm{SiO}_{2}$ and $\mathrm{Al}_{2} \mathrm{O}_{3}$ compared to the RMs (Table S2). The amorphous fraction corresponded to $\sim 50.4 \%$ (crystallinity was estimated in the $2-70^{\circ} 2 \theta$ range). The field dependence of magnetization (Figure 4c,d) of both FAnM and FARMp showed a ferromagnetic-like behavior. If this behavior was expected for sample FAnM, because SPIONs had been added during the synthesis process, the data obtained from FARMp confirm that, using FA as precursor, the magnetic behavior of the zeolites was dominated by ferrimagnetic oxides with spinel structure. This similarity is further confirmed by $\mathrm{H}_{\mathrm{c}}$ and $\mathrm{H}_{\mathrm{Cr}}$ values that were equal, within the experimental error, in both samples. Additionally, irreversible susceptibility showed a very good qualitatively agreement between the FAnM and FARMp samples and with SPIONs (Figure S2).

[a]

X-type zeolite

$\diamond$ Magnetite

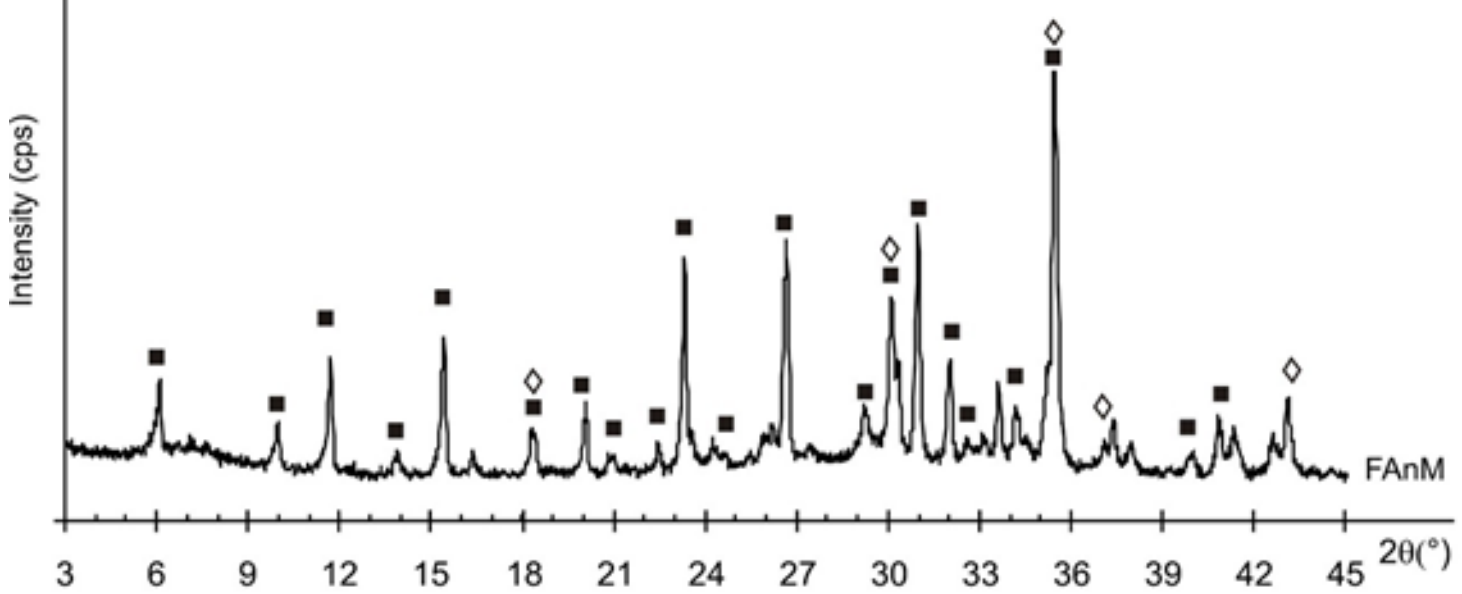

[b]

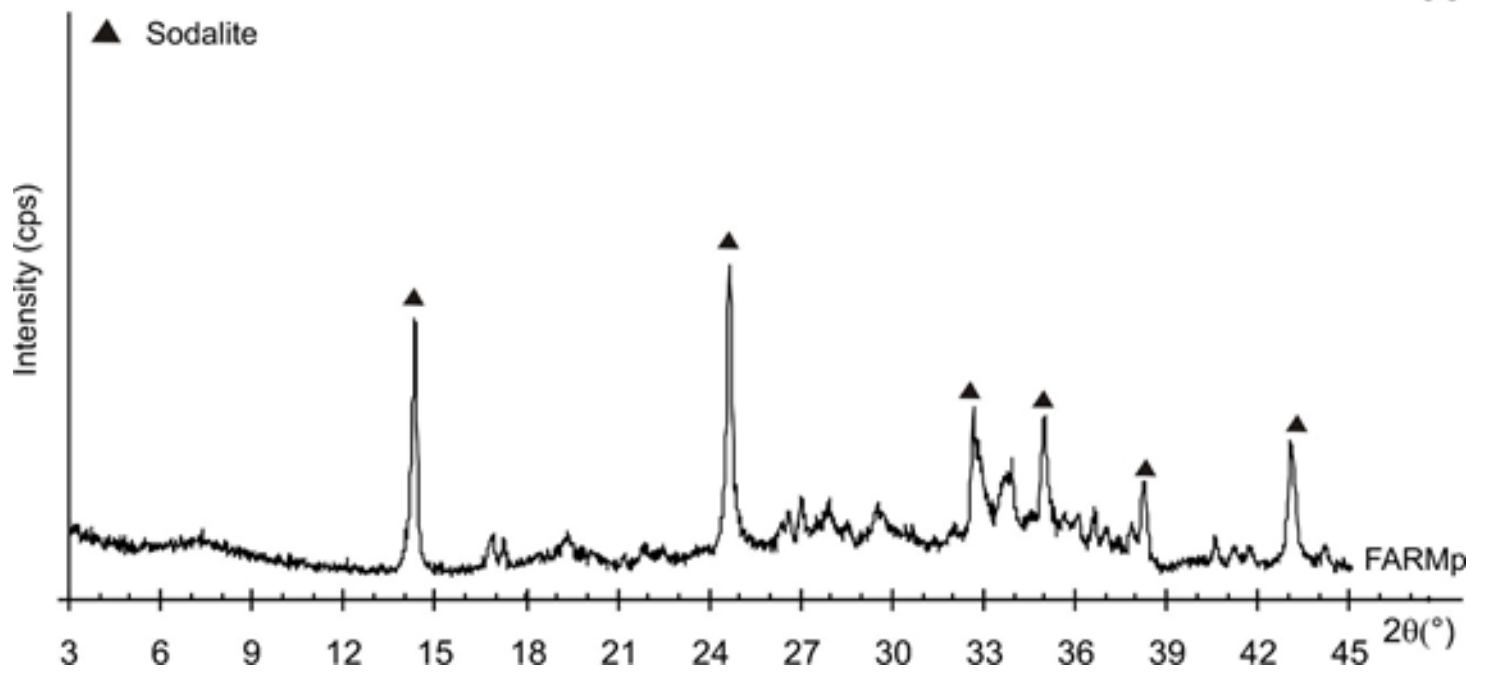

Figure 5. XRD patterns of: (a) FAnM and (b) FARMp samples. 


\subsection{Adsorption and Kinetic Behavior}

The adsorption efficiency of the investigated magnetic zeolites in OFL removal was studied in tap water because of its invariant composition and great similarity to environmental waters. Table S3 shows the physicochemical parameters of tap water from Pavia municipal waterworks and Ticino River.

\subsubsection{Preliminary Experiments}

For evaluating working $\mathrm{pH}, 50 \mathrm{mg}$ of each material was suspended in $10 \mathrm{~mL}$ of tap water not containing the drug and shaken overnight at room temperature. Subsequently, the adsorbent was removed for the $\mathrm{pH}$ measurement of the liquid phase. Due to the high $\mathrm{pH}$ values measured $(>10)$, several washing cycles were performed to eliminate any alkaline and salt residuals from the materials before use. After washing and air drying, $50 \mathrm{mg}$ of each material was re-suspended in $10 \mathrm{~mL}$ of tap water not containing the drug and treated as above. The measured $\mathrm{pH}$ values were in the range 8.3-8.9. The addition of $50 \mu \mathrm{L}$ of $1 \mathrm{M} \mathrm{HCl}$ allowed a $\mathrm{pH}$ of between 6.5 and 7.5, close to the environmental $\mathrm{pH}$. Quantities of 50,100, and $250 \mathrm{mg}$ of each material were suspended in $10 \mathrm{~mL}$ of tap water spiked with $10 \mathrm{mg} \mathrm{L}^{-1}$ OFL following the procedure described above (Section 2.5). The solution's $\mathrm{pH}$ was adjusted to around 7, adding appropriate amounts of $1 \mathrm{M} \mathrm{HCl}$. After equilibration ( $24 \mathrm{~h}$, room temperature, orbital shaker), the adsorbed OFL amount was calculated by Equation (1). As apparent in Figure S4, a moderate effect on the percentage of adsorbed OFL was observed, increasing the amount of the adsorbent materials. Thus, to guarantee the adsorption efficiency in the range $10-80 \%$ as indicated by ASTM D3860 guidelines [63] and to avoid an excess of waste, $100 \mathrm{mg}$ of each adsorbent were used in the experiments.

\subsubsection{Adsorption Experiments}

Different isotherm models-namely, the well-known Freundlich and Langmuir models and the BET model - were applied to describe OFL uptake onto SAnM, SARMs, FAnM, and FARMp. The Freundlich model is an empirical model used to describe non-ideal sorption, and Equation (3) expresses it:

$$
q_{e}=K_{F} C_{e}^{1 / n}
$$

where $K_{F}$ is the empirical constant indicative of sorption capacity, and $n$ is the empirical parameter indicative of the adsorption intensity.

The Langmuir model (Equation (4)) assumes that the adsorption process takes place at specific homogeneous sites and occurs in a monolayer that covers the surface of the material:

$$
q_{e}=\frac{q_{m} K_{L} C_{e}}{1+K_{L} C_{e}}
$$

where $K_{L}$ is the Langmuir constant and $q_{m}$ the monolayer saturation capacity.

The BET isotherm, adapted to describe liquid-phase adsorption [55] through multilayer adsorption, has the following form (Equation (5)):

$$
q_{e}=q_{m} \frac{K_{s} C_{e q}}{\left(1-K_{L}\right)\left(1-K_{L} C_{e q}+K_{s} C_{e q}\right)}
$$

where $\left(K_{S}\right)$ is the equilibrium constant for the first layer and $\left(K_{L}\right)$ is the equilibrium constant of potential upper layers.

The pseudo-first-order (Equation (6)) and pseudo-second-order (Equation (7)) used for describing the kinetic OFL uptake are:

$$
q_{t}=q_{e}\left(1-e^{-k_{1} t}\right)
$$




$$
q_{t}=\frac{\left(q_{e}^{2} k_{2} t\right)}{\left(1+q_{e} k_{2} t\right)}
$$

where $q_{t}$ and $q_{e}$ were the amount of OFL adsorbed at time $t$ and equilibrium, respectively; $k_{1}$ was the pseudo-first-order rate constant; and $k_{2}$ was the pseudo-second-order rate constant.

Figure 6 displays the experimental adsorption profiles of OFL on the different magnetic zeolite types, and Table S4 gathers the isotherm parameters obtained by fitting the experimental data using Freundlich, Langmuir, and BET models. The most relevant result is that all the zeolites considered adsorbed the OFL antibiotic efficiently, showing a similar trend well-described by the BET model (see Figure S5 and $\mathrm{R}^{2}$ values in Table S4). The calculated first-layer maximum adsorption capacity, $q_{m}$, is in good agreement with the experimental profiles (see the inflection point in Figure 6), and the highest values of $q_{\exp }$ confirmed that a multilayer absorption process occurred on the different zeolites investigated. FARMp and FAnM gave the highest OFL uptake, 11.6 and $8.5 \mathrm{mg} \mathrm{g}^{-1}$, respectively, compared with SARMs $\left(5.0 \mathrm{mg} \mathrm{g}^{-1}\right)$ and SAnM $\left(3.8 \mathrm{mg} \mathrm{g}^{-1}\right)$. Moreover, the first layer adsorption occurred faster for FARMp and FAnM than for SARMs and, in particular, SAnM.

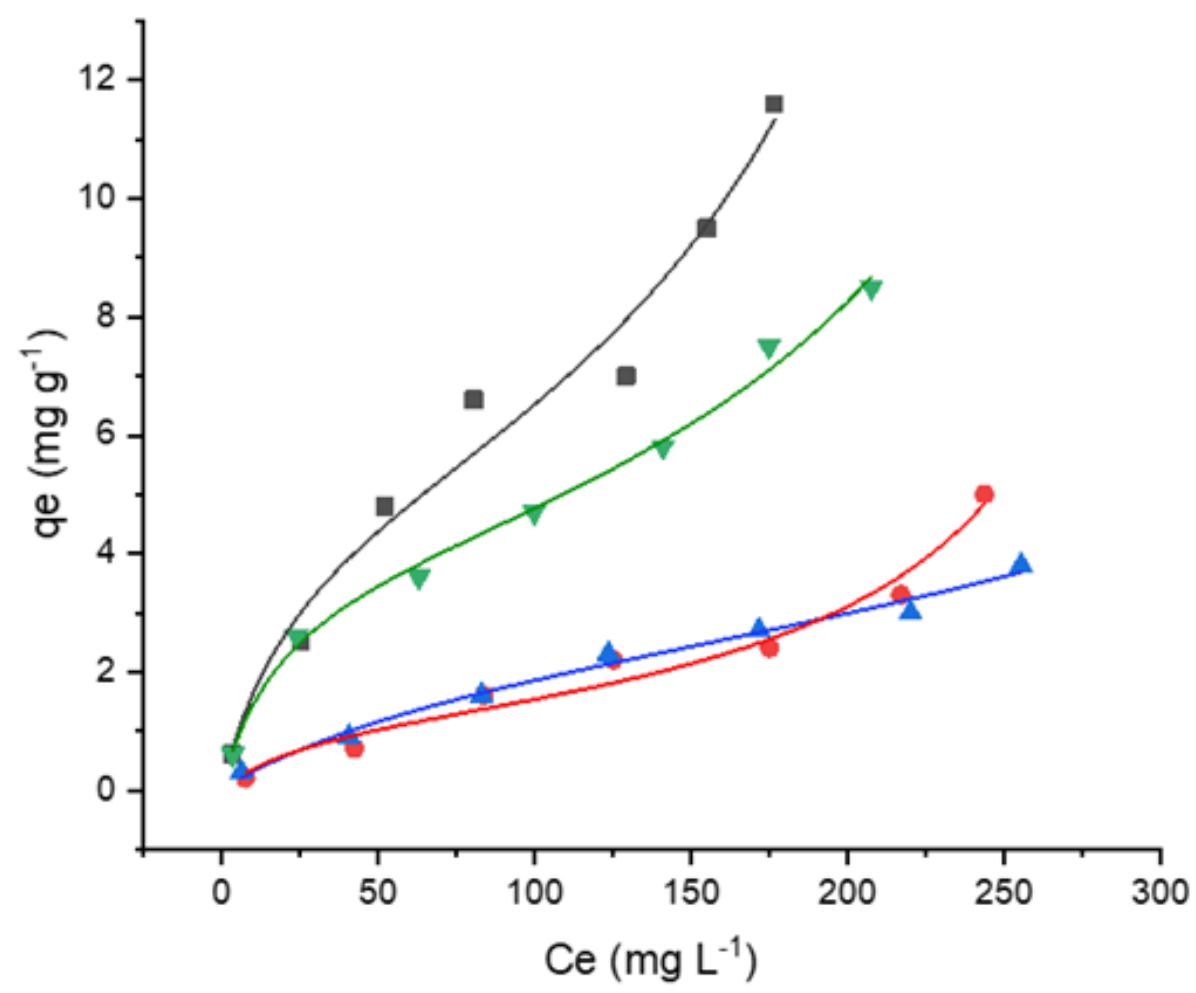

Figure 6. OFL Brunauer-Emmett-Teller (BET) profiles of SAnM $(\mathbf{\Delta})$, SARMs $(\boldsymbol{\bullet})$, FAnM $(\nabla)$, and

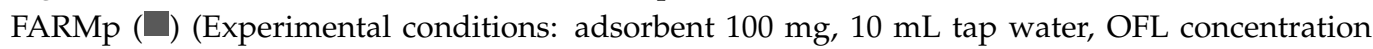
10-293 $\left.\mathrm{mg} \mathrm{L}^{-1}\right)$.

On the other hand, the samples synthesized by adding red mud (FARMp and SARMs) were more efficiently adsorbent than the respective samples synthesized using SPIONs (FAnM and SAnM, respectively). The addition of RM improved the adsorption performances, especially for FARMp. These differences in adsorption indicated that the solid matrices, including silica, alumina, and iron oxide, affect the adsorption of OFL from water, and hydrophobic and/or electrostatic interaction can be proposed as the driving mechanisms [58]. In addition, amorphous geopolymers create pores, thus increasing the surface area as well as the reactivity of the bead. At the same time, the affinity of synthesized phases towards OFL cannot be due solely to the chemical composition of the adsorbent materials, but also to their different topologies. Figure 1 shows the structures and chemical characteristics of the OFL antibiotic as well as those of synthesized zeolites. The OFL length is about $12.055 \AA$; indeed, the dimension of the molecule is about $7.10 \AA$ along the 
benzoxazine ring plane [66]. In FARMp, SARMs and SAnM samples, the OFL molecular dimensions are too large when compared to the zeolites' cavities (LTA topology, channels $<100>4.1 \times 4.1 \AA$; SOD topology, apertures formed by six rings only) [60,67]. On the contrary, the molecular dimension of OFL is slightly smaller than the free aperture of the 12-ring windows of the FAnM sample (FAU topology, channels $<111>127.4 \times 7.4$ ) [68]. The pore structure is characterized by approximately $12 \AA$ diameter cages, which are linked through access windows which are $7.0 \AA \times 7.1 \AA$ in diameter and are composed of rings of twelve linked tetrahedra (12-membered rings). The zeolites' CIF files taken from the IZA-SC Database of Zeolite Structures were used to calculate the pore dimensions, assuming an oxygen ionic radius of $1.35 \AA$ [69]. Thanks to these cages and windows, quite large molecules can enter therefore this structure is considered potentially useful in the adsorption of the antibiotics under study.

Consequently, we can reasonably speculate that OFL molecules are weakly bonded to the zeolite surface grains in FARMp, SARMs, and SAnM samples. Indeed, the dimensions of antibiotic molecules are compatible with the dimensions of the FAnM sample's cages thus suggesting that the adsorption of OFL can occur on both the surface grains and their porous structures.

Whit regard to the kinetic aspect, a fast OFL uptake-namely, 2 min for FARMp, SAnM, and SARMs, and 5 min for FAnM-occurred on all the investigated zeolites (see Figure S6 and Table S4). Consequently, a clear discrimination between the two kinetic models is not possible. Likewise, the calculated amounts of OFL absorbed $\left(q_{e}\right)$ are not significantly different from those experimentally obtained $\left(q_{e}\right.$ exp $)$ with both models.

Summing up, all zeolite types have a good affinity toward OFL. Unexpectedly, FARMp and FAnM, which were synthesized from waste, were more efficient than SARMs and SAnM in terms of adsorption capacity. Moreover, it is to be underlined that these synthetic products obey the principles of the circular economy. They employed industrial waste materials as precursors, which are low cost, easy to synthesize, and useful for water depollution. Moreover, they can be efficiently removed after the treatment due to their magnetic properties.

\subsubsection{Ofloxacin Adsorption under Environmental Conditions}

The suitability of SAnM, SARMs, FAnM, and FARMp as adsorbent phases for OFL removal from polluted waters was assessed on a river sample collected from Ticino River (Pavia, Northern Italy) spiked with low-level drug concentration $[47,56]$.

Each material (100 mg) was separately added to $10 \mathrm{~mL}$ water samples (tap and river water) spiked with $10 \mu \mathrm{g} \mathrm{L}^{-1} \mathrm{OFL}$, following the same procedure described in Section 2.5. The supernatants were then separated and analyzed by HPLC-FD to determine the amount of residual drug. The removal efficiency was calculated by Equation (8):

$$
\mathrm{R}=\frac{\left(C_{0}-C_{t}\right) \times V}{C_{0}} \times 100
$$

where $C_{0}$ is the initial OFL concentration and $C_{t}$ the OFL concentration after a contact time $t$. Table 2 shows the removal efficiencies obtained in the two aqueous matrices.

Interestingly, fly-ash-based materials gained higher recoveries than zeolites prepared from pure reagents, with no significant differences in \% R between FARMp and FAnM in both aqueous media. The presence of matrix constituents, such as NOM, anions, cations, $\mathrm{pH}$, and ionic strength did not significantly affect the adsorption process.

These preliminary data confirm that waste materials, such as red mud and fly ash, can form zeolites with magnetic behavior competitive in drug removal efficiency compared to feedstock under realistic conditions. 
Table 2. OFL removal efficiency ( $\%$ R) for FAnM, FARMp, SAnM, and SARMs in tap and river water samples (experimental conditions: adsorbent $100 \mathrm{mg}, 10 \mathrm{~mL}$ water sample, OFL concentration $\left.10 \mu \mathrm{g} \mathrm{L}^{-1}\right)$.

\begin{tabular}{lcc}
\hline & & $\mathbf{R} \%$ \\
\cline { 2 - 3 } Zeolite & Tap Water & River Water \\
\hline FAnM & 90 & 83 \\
FARMp & 92 & 87 \\
SAnM & 45 & 43 \\
SARMs & 63 & 61 \\
\hline RSD $\% \leq 10 \%$ & & \\
\hline
\end{tabular}

\section{Conclusions}

The data confirm that waste materials, such as red mud and fly ash, can be used to form zeolites with magnetic properties that can be modified adding pre-formed SPIONS during the synthesis process. In particular, sodalite synthesized using an FA and RM mixture (FARMp) shows ferromagnetic behavior due to the composition of fly ash and the red mud used, while the presence of red mud is responsible for antiferromagnetic behavior with a consequent important reduction in $\mathrm{M}_{\mathrm{S}}$ (SARMs sample) Finally, LTA and FAU topology formed by adding SPIONs during the synthesis process show a ferromagnetic behavior with a relatively higher saturation magnetization. All the synthetic zeolites adsorb a significant percentage of ofloxacin; materials formed from wastes are more effective in terms of their adsorption capacity, reducing the antibiotic concentration quantitatively in the presence of matrix constituents. Red mud acts to improve the adsorption performance, especially when added to fly ash, forming a zeolite with SOD topology in FARMp. OFL adsorption occurs on both the surface grains and porous structures of the FAU topology characterizing the FAnM sample.

Supplementary Materials: The following are available online at https: / www.mdpi.com/article/ 10.3390/pr9122137/s1, Figure S1: XRD patterns of: (a) RMs; (b) RMp and (c) FA, Figure S2: Irreversible magnetic susceptibility for FAnM and FARM samples, Figure S3: (a) Field dependence of magnetization (full circlee) and DCD remenence magnetization (empty cicles) recorded at $300 \mathrm{~K}$; (b) irreversible susceptibility extracted from DCD, Figure S4: \% adsorbed OFL vs. adsorbent amount

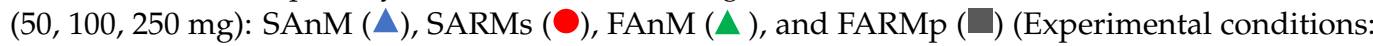
$10 \mathrm{~mL}$ tap water, OFL concentration $\left.10 \mathrm{~L}^{-1}\right)$, Figure S5: Adsorption profiles Langmuir (-), Freundlich (_) and BET ( . . ) for OFL on (a) FARMp, (b) FanM, (c) SARMs and (d) SAnM, (Experimental conditions: $100 \mathrm{mg}, 10 \mathrm{~mL}$ tap water, OFL solution from 10 to $293 \mathrm{mg} \mathrm{L}^{-1}$ ), Figure S6: Kinetic profiles (pseudo-first order (_) and pseudo-second (..) order) for OFL on (a) FARMp, (b) FAnM, (c) SARMs and (d) SAnM (Experimental conditions: $200 \mathrm{mg}, 20 \mathrm{~mL}$ tap water, OFL initial concentration $20 \mathrm{mg} \mathrm{L}^{-1}$ ), Table S1: Sample synthesis, Table S2: XRF chemical composition of red muds (RM) and fly ash (FA) $(\mathrm{w} t \%)$, Table S3: Isotherm parameters obtained by fitting the experimental data for OFL adsorption onto SAnM, SARMs, FAnM, and FARMp. (Experimental conditions: $100 \mathrm{mg}$ adsorbent phase, $10 \mathrm{~mL}$ tap water, OFL concentrations from 10 to $293 \mathrm{mg} \mathrm{L}^{-1}$ ), Table S4: Municipal water of Pavia and Ticino River physico-chemical parameters. Conductivity $\left(\mu \mathrm{S} \mathrm{cm}^{-1}\right)$; other parameters $\left(\mathrm{mg} \mathrm{L}^{-1}\right)$.

Author Contributions: C.B.: conceptualization, investigation, formal analysis, writing-original draft; G.G.: formal analysis, writing — original draft; M.A.: formal analysis, writing —original draft; D.P.: writing-original draft; F.M.: formal analysis; F.C.: writing—original draft; M.F.: writingoriginal draft; A.M.: writing—original draft; M.S.: conceptualization, investigation, writing—original draft. All authors have read and agreed to the published version of the manuscript.

Funding: This research received no external funding.

Institutional Review Board Statement: Not applicable.

Informed Consent Statement: Not applicable. 
Data Availability Statement: The raw/processed data required to reproduce these findings cannot be shared at this time due to technical or time limitations.

Conflicts of Interest: The authors declare that they have no known competing financial interests or personal relationships that could have appeared to influence the work reported in this paper.

\section{References}

1. Coombs, D.S.; Alberti, A.; Armbruster, T.; Artioli, G.; Colella, C.; Galli, E.; Grice, D.; Liebau, F.; Mandarino, J.A.; Minato, H.; et al. Recommended nomenclature for zeolite minerals: Report of the subcommittee on zeolites of the International Mineralogical Association, Commission on New Minerals and Mineral Names. Can. Mineral. 1997, 35, 1571-1606.

2. Čejka, J.; Millini, R.; Opanasenko, M.; Serrano, D.P.; Roth, J. Advances and challenges in zeolite synthesis and catalysis. Catal. Today 2020, 345, 2-13. [CrossRef]

3. Bellussi, G.; Carati, A.; Rizzo, C.; Millini, R. New trends in the synthesis of crystalline microporous materials. Catal. Sci. Tech. 2013, 3, 833-857. [CrossRef]

4. Weckhuysen, B.M.; Yu, J. Recent advances in zeolite chemistry and catalysis. Chem. Soc. Rev. 2015, 44, 7022-7024. [CrossRef]

5. Li, J.; Corma, A.; Yu, J. Synthesis of new zeolite structures. Chem. Soc. Rev. 2015, 44, 7112-7127. [CrossRef] [PubMed]

6. Li, C.; Moliner, M.; Corma, A. Building zeolites from precrystallized units: Nanoscale architecture. Angew. Chem. Int. Ed. 2018, 57, 15330-15353. [CrossRef]

7. Oste, L.A.; Lexmond, T.M.; Van Riemsdijk, W.H. Metal immobilization in soils using synthetic zeolites. J. Environ. Qual. 2002, 31, 813-821. [CrossRef] [PubMed]

8. Mahabadi, A.A.; Hajabbasi, M.A.; Khademi, H.; Kazemian, H. Soil cadmium stabilization using an Iranian natural zeolite. Geoderma 2007, 137, 388-393. [CrossRef]

9. Li, H.; Shi, W.; Shao, H.; Shao, M. The remediation of the lead-polluted garden soil by natural zeolite. J. Hazard. Mater. 2009, 169, 1106-1111. [CrossRef]

10. Belviso, C.; Cavalcante, F.; Ragone, P.; Fiore, S. Immobilization of Ni by synthesising zeolite at low temperatures in a polluted soil. Chemosphere 2010, 78, 1172-1176. [CrossRef]

11. Misaelides, P. Application of natural zeolites in environmental remediation: A short review. Micropor. Mesopor. Mat. 2011, 144, 15-18. [CrossRef]

12. Belviso, C.; Cavalcante, F.; Ragone, P.; Fiore, S. Immobilization of $\mathrm{Zn}$ and $\mathrm{Pb}$ in polluted soil by in-situ crystallization zeolites from fly ash. Water Air Soil Pollut. 2012, 223, 5357-5364. [CrossRef]

13. Boros-Lajszner, E.; Wyszkowska, J.; Kucharski, J. Use of zeolite to neutralise nickel in a soil environment. Environ. Monit. Assess. 2018, 190, 54. [CrossRef]

14. Belviso, C. Zeolite for potential toxic metals uptake from contaminated soil: A brief review. Processes 2020, 8, 820. [CrossRef]

15. Sprynskyy, M.; Buszewski, B.; Terzyk, A.P.; Namiesnik, J. Study of the selection mechanism of heavy metal $\left(\mathrm{Pb}^{2+}, \mathrm{Cu}^{2+}, \mathrm{Ni}^{2+}\right.$, and $\mathrm{Cd}^{2+}$ ) adsorption on clinoptilolite. J. Colloid Interface Sci. 2006, 304, 21-28. [CrossRef] [PubMed]

16. Maretto, M.; Blanchi, F.; Vignola, R.; Canepari, S.; Baric, M.; Iazzoni, R.; Tagliabue, M.; Papini, M.P. Microporous and mesoporous materials for the treatment of wastewater produced by petrochemical activities. J. Clean. Prod. 2014, 77, 22-34. [CrossRef]

17. Martucci, A.; Braschi, I.; Marchese, L.; Quartieri, S. Recent advances in clean-up strategies of waters polluted with sulfonamide antibiotics: A review of sorbents and related properties. Mineral. Mag. 2014, 78, 1115-1140. [CrossRef]

18. Bandura, L.; Woszuk, A.; Kołodynska, D.; Franus, W. Application of mineral sorbents for removal of petroleum substances: A review. Minerals 2017, 7, 37. [CrossRef]

19. Mancinelli, M.; Arfè, A.; Martucci, A.; Pasti, L.; Chenet, T.; Sarti, E.; Vergine, G.; Belviso, C. Evaluation for the removal efficiency of VOCs and heavy metals by zeolites-based materials in the wastewater: A case study in the Tito Scalo industrial area. Processes 2020, 8, 1519. [CrossRef]

20. Rodeghero, E.; Chenet, T.; Martucci, A.; Ardit, M.; Sarti, E.; Pasti, L. Selective adsorption of toluene and n-hexane binary mixture from aqueous solution on zeolite ZSM-5: Evaluation of competitive behavior between aliphatic and aromatic compounds. Catal. Today 2020, 345, 157-164. [CrossRef]

21. Mintova, S.; Olson, N.H.; Valtchev, V.; Bein, T. Nanocrystal growth from colloids at room temperature. Science 1999, 28, 958-960. [CrossRef]

22. Matthew, D.O.; Soltis, J.A.; Marlon, T.C.; Lee Penn, R.; Rimer, J.D. Nucleation of FAU and LTA zeolites from heterogeneous aluminosilicate precursors. Chem. Mater. 2016, 28, 4906-4916.

23. Belviso, C. EMT-type zeolite synthesized from obsidian. Micropor. Mesopor. Mat. 2016, 226, 325-330. [CrossRef]

24. Belviso, C.; Peddis, D.; Varvaro, G.; Abdolrahimi, M.; Reverberi, A.P.; Cavalcante, F. Obsidian as raw material for eco-friendly synthesis of magnetic zeolite. Materials 2020, 13, 4633. [CrossRef]

25. Psycharis, V.; Perdikatsis, V.; Christidis, G. Crystal structure and Rietveld refinement of zeolite A synthesized from fine-grained perlite waste materials. Bull. Geol. Soc. Greece 2004, 36, 121-129. [CrossRef]

26. Shawabkeh, R.; Al-Harahsheh, A.; Hami, M.; Khlaifat, A. Conversion of oil shale ash into zeolite for cadmium and lead removal from wastewater. Fuel 2004, 83, 981-985. [CrossRef]

27. Qian, T.; Li, J. Synthesis of Na-A zeolite from coal gangue with the in-situ crystallization technique. Adv. Powder Technol. 2015, 26, 98-104. [CrossRef] 
28. Ng, E.-P.; Awala, H.; Tan, K.H.; Adam, F.; Retoux, R.; Mintova, S. EMT-type zeolite nanocrystals synthesized from rice husk. Micropor. Mesopor. Mat. 2015, 204, 2014-2209. [CrossRef]

29. Ma, D.; Wang, Z.; Guo, M.; Zhang, M.; Liu, J. Feasible conversion of solid waste bauxite tailings into highly crystalline 4A zeolite with valuable application. Waste Manag. 2014, 34, 2365-2372. [CrossRef]

30. Liu, L.; Du, T.; Li, G.; Yang, F.; Che, S. Using one waste to tackle another: Preparation of a CO2 capture material zeolite X from laterite residue and bauxite. J. Hazard. Mater. 2014, 278, 551-558. [CrossRef]

31. Belviso, C.; Agostinelli, E.; Belviso, S.; Cavalcante, F.; Pascucci, S.; Peddis, D.; Varvaro, G.; Fiore, S. Synthesis of magnetic zeolite at low temperature using a waste material mixture: Fly ash and red mud. Micropor. Mesopor. Mat. 2015, 202, 208-216. [CrossRef]

32. Belviso, C.; Kharchenko, A.; Agostinelli, E.; Cavalcante, F.; Peddis, D.; Varvaro, G.; Yaacoub, N.; Mintova, S. Red mud as aluminium source for the synthesis of magnetic zeolite. Micropor. Mesopor. Mat. 2018, 270, 24-29. [CrossRef]

33. Cheng, Y.; Xu, L.; Jiang, Z.; Liu, C.; Zhang, Q.; Zou, Y.; Chen, Y.; Li, J.; Liu, X. Feasible low-cost conversion of red mud into magnetically separated and recycled hybrid SrFe12O19@ NaP1 zeolite as a novel wastewater adsorbent. Chem. Eng. J. 2020, 417, 128090. [CrossRef]

34. Belviso, C.; Cannas, C.; Pinna, N.; Cavalcante, F.; Lettino, A.; Lotti, P.; Gatta, G.D. Effect of red mud added to zeolite LTA synthesis: Where is Fe in the newly-formed material? Micropor. Mesopor. Mat. 2020, 298, 1100583. [CrossRef]

35. Oliveira, L.C.A.; Petkowicz, D.I.; Smaniotto, A.; Pergher, S.B.C. Magnetic zeolites: A new adsorbent for removal of metallic contaminants from water. Water Res. 2004, 38, 3699-3704. [CrossRef]

36. Nguyen, T.C.; Loganathan, P.; Nguyen, T.V.; Vigneswaran, S.; Kandasamy, J.; Naidu, R. Simultaneous adsorption of Cd, Cr, $\mathrm{Cu}, \mathrm{Pb}$, and $\mathrm{Zn}$ by an iron-coated Australian zeolite in batch and fixed-bed column studies. Chem. Eng. J. 2015, 270, 393-404. [CrossRef]

37. Alberti, S.; Caratto, V.; Peddis, D.; Belviso, C.; Ferretti, M. Synthesis and characterization of a new photocatalyst based on TiO 2 nanoparticles supported on a magnetic zeolite from iron and steel industrial waste. J. Alloys Compd. 2019, 797, 820-825. [CrossRef]

38. Faghihian, H.; Moayed, M.; Firooz, A.; Iravani, M. Synthesis of a novel magnetic zeolite nanocomposite for removal of Cs ${ }^{+}$ and $\mathrm{Sr}^{2+}$ from aqueous solution: Kinetic, equilibrium, and thermodynamic studies. J. Colloid Interface Sci. 2013, 393, 445-451. [CrossRef]

39. Ifthikar, J.; Wang, J.; Wang, Q.; Wang, T.; Wang, H.; Khan, A.; Jawad, A.; Sun, T.; Jiao, X.; Chen, Z. Highly efficient lead distribution by magnetic sewage sludge biochar: Sorption mechanisms and bench applications. Biores. Technol. 2017, 238, 399-406. [CrossRef]

40. Braschi, I.; Blasioli, S.; Gigli, L.; Gessa, C.E.; Alberti, A.; Martucci, A. Removal of sulfonamide antibiotics from water: Evidence of adsorption into an organophilic zeolite Y by its structural modifications. J. Hazard. Mat. 2010, 178, 218-225. [CrossRef] [PubMed]

41. Martucci, A.; Pasti, L.; Marchetti, N.; Cavazzini, A.; Dondi, F.; Alberti, A. Adsorption of pharmaceuticals from aqueous solutions on synthetic zeolites. Micropor. Mesopor. Mat. 2012, 148, 174-183. [CrossRef]

42. Deo, R.P. Pharmaceuticals in the surface water of the USA: A review. Curr. Environ. Health Rep. 2014, 1, 113-122. [CrossRef]

43. Eslami, A.; Amini, M.M.; Yazdanbakhsh, A.R.; Rastkari, N.; Mohseni-Bandpei, A.; Nasseri, S.; Piroti, E.; Asadi, A. Occurrence of non-steroidal anti-inflammatory drugs in Tehran source water, municipal and hospital wastewaters, and their ecotoxicological risk assessment. Environ. Monit. Assess. 2015, 187, 1-15. [CrossRef]

44. Castiglioni, S.; Davoli, E.; Riva, F.; Palmiotto, M.; Camporini, P.; Manenti, A.; Zuccato, E. Mass balance of emerging contaminants in the water cycle of a highly urbanized and industrialized area of Italy. Water Res. 2018, 131, 287-298. [CrossRef]

45. Gogoi, A.; Mazumder, P.; Tyagi, V.K.; Tushara, G.G.; Chaminda, A.K.; Kumar, M. Occurrence and fate of emerging contaminants in water environment: A review. Ground W. Sustain. Dev. 2018, 6, 169-180. [CrossRef]

46. Sauvé, S.; Desrosiers, M. A review of what is an emerging contaminant. Chem. Cent. J. 2014, 8, 15-21. [CrossRef]

47. Sousa, J.C.G.; Ribeiro, A.R.; Barbosa, M.O.; Fernando, M.; Pereira, R.; Silva, A.M.T. A review on environmental monitoring of water organic pollutants identified by EU guidelines. J. Hazard. Mater. 2018, 344, 146-162. [CrossRef] [PubMed]

48. European Commission, Communication from the Commission to the European Parliament, the Council, and the European Economic and Social Committee: European Union Strategic Approach to Pharmaceuticals in the Environment. Communication 2019, 128, 13.

49. Merlin, C. Reducing the consumption of antibiotics: Would that be enough to slow down the dissemination of resistances in the downstream environment? Front. Microbiol. 2020, 11, 33. [CrossRef] [PubMed]

50. Sturini, M.; Maraschi, F.; Cantalupi, A.; Pretali, L.; Nicolis, S.; Dondi, D.; Profumo, A.; Caratto, V.; Sanguineti, E.; Ferretti, M.; et al. $\mathrm{TiO}_{2}$ and $\mathrm{N}-\mathrm{TiO}_{2}$ sepiolite and zeolite composites for photocatalytic removal of ofloxacin from polluted water. Materials 2020, 13, 537-550. [CrossRef]

51. Sarti, E.; Chenet, T.; Stevanin, C.; Costa, V.; Cavazzini, A.; Catani, M.; Martucci, A.; Precisvalle, N.; Beltrami, G.; Pasti, L. High-silica zeolites as sorbent media for adsorption and pre-concentration of pharmaceuticals in aqueous solutions. Molecules 2020, 25, 3331. [CrossRef]

52. Rivagli, E.; Pastorello, A.; Sturini, M.; Maraschi, F.; Speltini, A.; Zampori, L.; Setti, M.; Malavasi, L.; Profumo, A. Clay minerals for adsorption of veterinary FQs: Behavior and modelling. J. Environ. Chem. Eng. 2014, 2, 738-744. [CrossRef]

53. Maraschi, F.; Sturini, M.; Speltini, A.; Pretali, L.; Profumo, A.; Pastorello, A.; Kumar, V.; Ferretti, M.; Caratto, V. TiO 2 -modified zeolites for fluoroquinolones removal from wastewaters and re-use after solar light regeneration. J. Environ. Chem. Eng. 2014, 2 , 2170-2176. [CrossRef] 
54. Sturini, M.; Speltini, A.; Maraschi, F.; Profumo, A.; Tarantino, S.; Gualtieri, A.F.; Zema, M. Removal of fluoroquinolone contaminants from environmental waters on sepiolite and its photo-induced regeneration. Chemosphere 2016, 150, 686-693. [CrossRef] [PubMed]

55. Capsoni, D.; Guerra, G.; Puscalau, C.; Maraschi, F.; Bruni, G.; Monteforte, F.; Profumo, A.; Sturini, M. Zinc based metal-organic frameworks as ofloxacin adsorbents in polluted waters: ZIF-8 vs. $\mathrm{Zn}_{3}(\mathrm{BTC})_{2}$. Int. J. Environ. Res. Public Health 2021, $18,1433$. [CrossRef] [PubMed]

56. Ateia, M.; Helbling, D.E.; Dichtel, W.R. Best practices for evaluating new materials as adsorbents for water treatment. ACS Mater. Lett. 2020, 2, 1532-1544. [CrossRef]

57. Liu, Q.; Barrón, V.; Torrent, J.; Qin, H.; Yu, Y. The magnetism of micro-sized hematite explained. Phys. Earth Planet. Inter. 2010, 183, 387-397. [CrossRef]

58. Robberson, K.A.; Waghe, A.B.; Sabatini, D.A.; Butler, E.C. Adsorption of the quinolone antibiotic nalidixic acid onto anionexchange and neutral polymers. Chemosphere 2006, 63, 934-941. [CrossRef]

59. Mahapatra, S.; Venugopala, K.N.; Guru, T.N.; Row, A. A device to crystallize organic solids: Structure of ciprofloxacin, midazolam, and ofloxacin as targets. Cryst. Growth Des. 2010, 10, 1866-1870. [CrossRef]

60. Gramlich, V.; Meier, W.M. The crystal structure of hydrated NaA: A detailed refinement of a pseudosymmetric zeolite structure. Z. Kristallogr. 1971, 133, 134-149. [CrossRef]

61. Belviso, C.; Cavalcante, F.; Fiore, S. Synthesis of zeolite from Italian coal fly ash. Differences in crystallization temperature using seawater instead of distilled water. Waste Manag. 2010, 30, 839-847. [CrossRef] [PubMed]

62. Bruker AXS. DIFFRAC. EVA V5.1; Bruker AXS GmbH: Karlsruhe, Germany, 2019.

63. ASTM. Standard Practice for Determination of Adsorption Capacity of Activated Carbon by Aqueous Phase Isotherm Technique; American Society of Testing and Materials; Annual Book of ASTM Standards; ASTM: West Conshohocken, PA, USA, 1998.

64. Walker, M.; Majo, P.I.; O'Grady, K.; Charles, S.W.; Chantrell, R.W. The magnetic properties of single-domain particles with cubic anisotropy. II. Remanence curves. J. Phys. Condens. Matter. 1993, 5, 2793. [CrossRef]

65. Laureti, S.; Varvaro, G.; Fiorani, D.; Agostinelli, E.; Piccaluga, G.; Musinu, A.; Ardu, A.; Peddis, D. Magnetic interactions in silica coated nanoporous assemblies of $\mathrm{CoFe}_{2} \mathrm{O}_{4}$ nanoparticles with cubic magnetic anisotropy. Nanotechnology 2010, $21,315701$. [CrossRef]

66. Suber, P.; Imperatori, P.; Mari, A.; Marchegiani, G.; Mansilla, M.V.; Fiorani, D.; Plunkett, W.R.; Rinaldi, D.; Cannas, C.; Ennas, G.; et al. Thermal hysteresis of Morin transition in hematite particles. Phys. Chem. Chem. Phys. 2010, 12, 6984-6989. [CrossRef] [PubMed]

67. Loens, J.; Schulz, H.; Strukturverfeinerung von Sodalith, $\mathrm{H} . \mathrm{Na}_{8} \mathrm{Si}_{6} \mathrm{Al}_{6} \mathrm{O}_{24} \mathrm{Cl}_{2}$. Acta Crystallogr. 1967, $23,434-436$.

68. Baur, W.H. On the cation and water positions in faujasite. Am. Mineral. 1964, 49, 697-704.

69. Baerlocher, C.H.; McCusker, L.B. Database of Zeolite Structures. 2017. Available online: http:/ / www.iza-structure.org/databases/ (accessed on 24 November 2021). 